\title{
Quo vadis? Historical distribution and impact of climate change on the worldwide distribution of the Australasian fungus Clathrus archeri (Phallales, Basidiomycota)
}

\author{
Marcin Pietras $^{1}$ (D) - Marta Kolanowska ${ }^{2,3}$ (D) Marc-André Selosse M,5 $^{4}$
}

Received: 16 July 2020 / Revised: 5 January 2021 / Accepted: 7 January 2021 /

(C) The Author(s) 2021

\begin{abstract}
Clathrus archeri is a fungus native to Australia and New Zealand that has started to expand into Europe, and it is considered a potentially invasive species. In this study, we examine the historical occurrence, current geographical range and potential future changes in the distribution of $C$. archeri using worldwide distribution data. Ecological modelling was used to assess the locations of the potential climatic niches of $C$. archeri within both its native and introduced ranges in the past, present and future. Our study clearly shows that the coverage of suitable habitats of this fungus has decreased since the last glacial maximum, and anthropogenic climate changes are accelerating the process of niche loss. The highest rate of $C$. archeri range contraction is expected in Australia, where the fungus should be considered a threatened species in the future. Highly valuable habitats will be available in Tasmania and New Zealand. However, a significant expansion rate of $C$. archeri will still probably be observed in Europe, where the climatic conditions preferred by the fungus will allow its quick expansion northeast into the continent.
\end{abstract}

Keywords Clathrus archeri $\cdot$ Devil's finger fungus $\cdot$ Biological invasions $\cdot$ Species distribution modelling $\cdot$ Fungal biogeography

\section{Introduction}

Climate is one of the most important factors explaining species distributions (Moura et al. 2016), and global warming is

Section Editor: Claus Baessler

Marcin Pietras

mpietras@man.poznan.pl

1 Institute of Dendrology, Polish Academy of Sciences, Parkowa 5, 62-035 Kórnik, Poland

2 Department of Geobotany and Plant Ecology, Faculty of Biology and Environmental Protection, University of Lodz, Banacha 12/16, 90-237 Lodz, Poland

3 Department of Biodiversity Research, Global Change Research Institute AS CR, Bělidla 4a, 60300 Brno, Czech Republic

4 Department of Plant Taxonomy and Nature Conservation, Faculty of Biology, University of Gdańsk, ul. Wita Stwosza 59, 80-308 Gdańsk, Poland

5 Institut de Systématique, Evolution, Biodiversité (ISYEB), Muséum national d'Histoire naturelle, CNRS, Sorbonne Université, EPHE, CP 39, 57 rue Cuvier, 75005 Paris, France thereby a significant threat to biodiversity, as it may affect animal (Radchuk et al. 2019), plant (Suggitt et al. 2019), and fungal communities (Větrovský et al. 2019) as well as entire ecosystems (Walther 2010). Climate changes strongly influence the abundances and distribution of numerous organisms, and these changes can cause latitudinal or altitudinal range shifts. Global warming can also enhance the spread of some organisms, including exotic ones (Hellmann et al. 2008; Dyderski et al. 2017).

As defined by the International Union for Conservation of Nature (IUCN), an invasive species (invader) is an alien organism introduced beyond the area where it occurs naturally. The introduction of invasive species is an agent of change and threatens native biodiversity (http://www.issg.org ${ }^{1}$ ). Invasive species can be animals, plants, or fungi that are introduced accidentally or deliberately into a place where they are not normally found. Studies on anthropogenic introductions focus mainly on animals and plants, with too few investigations into microbial species, especially fungi (but see Desprez-Loustau et al. 2007). In contrast to macroorganisms, the occurrence of fungi is often difficult to detect without concerted efforts or costly molecular tools.

\footnotetext{
${ }^{1} \mathrm{http}: / /$ www.issg.org
} 
Apart from fungal pathogens, which cause major ecological impacts on plants and animals, the biogeography and influence of other invasive fungi often remain poorly recognized. According to another definition (Blackburn et al. 2011), the term 'invasive' can be used for organisms (including fungi) with self-sustaining populations at significant distances from their places of original introduction. The crucial difference between these two definitions is the ability of the particular species to threaten biological diversity in the invaded areas.

The few existing biogeographic studies of non-pathogenic fungi have focused mainly on mycorrhizal fungi (Hao et al. 2020). Suilloid fungi, which were cointroduced with their pine tree mycorrhizal partners, are among the well-described examples showing the biogeography and probable pathways of introduction (Vellinga et al. 2009; Pietras et al. 2018; Pietras 2019; Pietras and Kolanowska 2019; Policelli et al. 2019). Descriptions of the introduction of wood-inhabiting Favolaschia calocera to Italy (Vizzini et al. 2009), saprobic Amanita inopinata (Fraiture and di Giangregorio 2013) to Belgium, and ectomycorrhizal Amanita phalloides (Pringle and Vellinga 2006; Pringle et al. 2009) to the USA are among the few examples of the well-described introduction pathways of fungi.

Clathrus archeri (Berk.) Dring is a saprobic fungus native to Australia, but it is also frequently recorded in New Zealand. In its native range, the fungus has been detected mainly in mountainous regions and across seasides, where it forms sporocarps on the wood debris of eucalypt and nothofagus trees. Currently, it is also frequently recorded in gardens, parks, and other urban areas as a result of the transport and use of wood chips and mulch for gardening. Since the beginning of the twentieth century, it has been gradually spreading throughout the world. Currently, sporocarps of $C$. archeri are found in North and South America, but the highest concentration of introduced records are from Europe, where it grows mainly in broadleaf and mixed forests and beyond forest areas in gardens, orchards, old cemeteries and meadows (StenglRejthar and Wojewoda 1985). According to Bãžrsan et al. (2014), C. archeri has no special habitat preferences and occurs frequently on different soil types, commonly forming sporocarps on wood debris, mulch, and forest litter. However, the fungus avoids calcareous soils (Parent et al. 2000; Bãžrsan et al. 2014). Reports on the distribution of $C$. archeri in Europe are mostly embedded as short notes or snippets in regional lists since 1920 (Parent and Thoen 1986). Our previous research conducted in Poland indicated that even at the scale of a single country, latitudinal shifts in the geographical distribution of $C$. archeri could be detected in a relatively short time period (Pietras et al. 2016). Outside its native range, the impact of $C$. archeri on native ecosystems is unknown. Negative effects of the fungus on native ecosystems have not been proven so far regarding either its interactions with native mycobiota or its influence on soil biochemistry.
Therefore, based on the IUCN definition, $C$. archeri cannot yet be termed "invasive" but is rather considered potentially invasive.

The aim of the present study was to present the climaterelated ecology of $C$. archeri. We chose this fungus because it is a highly suitable model species for invasion ecology research due to the availability and reliability of associated data (both in its native and introduced ranges: GBIF.org, 26 October 2018a, 2018b, respectively; including disjunct occurrences: GBIF.org, 26 October 2018c) and its set of distinct morphological features, which make it easy to identify under field conditions. Considering all these aspects, $C$. archeri can be regarded as a model organism in studies describing the biogeography and invasion ecology of nonpathogenic fungi (Dickie et al. 2016). Additionally, we evaluated the similarities between the bioclimatic niches occupied by native and introduced populations of $C$. archeri. The impact of global warming on the future distribution of this species was further assessed using a species distribution modelling approach. Our research focused on estimations of the locations of suitable C. archeri habitats during the last glacial maximum (LGM; approximately 22,000 years ago) and on resolving its status in New Zealand, where the fungus is suspected to be nonnative.

\section{Methods}

\section{List of localities}

Data on the current distribution of $C$. archeri were gathered from the literature, herbaria, the Global Biodiversity Information Facility $\left(\mathrm{GBIF}^{2}\right)$ and our own extensive field survey. Out of 2222 records submitted to GBIF (31 December 2019) we select only localities of preserved specimens. This approach give possibility to eliminate observations, that could be easily misidentified and confused with other closely-related taxa such as Aseroe rubra - a fungus that occurs in the same area in Australia and New Zealand. Direct use of all GBIF records could be also biased because of autocorrelation of several closely located (in the same $21.62 \mathrm{~km}^{2}$ equator) records. Locations for which the exact geographic coordinates were available were used exclusively in further analyses. From a total of 150 locations of $C$. archeri assembled during this study, the multiple species records from each grid cell were removed. A final database included 146 occurrence data (Appendix).

\section{Species distribution modelling}

The species distribution modelling was conducted using the maximum entropy method implemented in MaxEnt version

\footnotetext{
$\overline{2 \text { www.gbif.org }}$
} 
3.3.2 (Phillips et al. 2004, 2006) based on the species presence-only observations. We use MaxEnt application because its prediction accuracy is stable and reliable, even with limited data and small sample sizes (Phillips et al. 2006; Guo et al. 2017). The dataset of 146 records, which is more than the minimum number of records ( 10 observed localities) required to obtain reliable predictions in the MaxEnt application (Pearson et al. 2006; Wisz et al. 2008), was used as input data. Because niche shifts were observed in some invasive species (e.g., González-Moreno et al. 2015), we decided to conduct separated assessment for populations of $C$. archeri in its native range. For that reason two different approaches were used to conduct analysis. In the first, locations from Australia and New Zealand (58 records) were exclusively used. In the second, all available records of the studied species (58 from Australia and New Zealand, 88 from Europe and South Africa) were included in the modelling. From 19 climatic variables ("bioclims", Table 1) in 2.5 arc minutes ( \pm $21.62 \mathrm{~km}^{2}$ at the equator) as developed by Hijmans et al. (2005) and provided by WorldClim (version 1.4 release 3, www.worldclim.org ${ }^{3}$ ), seven variables were removed due to their significant correlation (above 0.9 ) as evaluated by the Pearsons' correlation coefficient calculated using ENMTools v1.3. The following variables were excluded from the dataset: bio6, bio7, bio9, bio10, bio11, bio16, and bio17 (Table 1).

In all analyses, the maximum number of iterations was set to 10,000 and the convergence threshold to 0.00001 . The "random seed" option, which provided random test partition and background subset for each run, was applied. The run was performed as a bootstrap with 1000 replicates, and the output was set to logistic. All operations on GIS data were carried out on ArcGis 10.6 (ESRI) and QGIS 2.18.20.

\section{Niche similarity}

The differences between the niches occupied by the native and introduced populations of $C$. archeri (as calculated in ENM analyses) were evaluated using the niche identity test indexes: Schoener's D and I statistic as available in ENMTools v1.3 (Schoener 1968; Warren et al., 2008, 2010). To visualize the difference between the climatic preferences of both groups of populations, the predicted niche occupancy profiles (PNOs) were created using the Phyloclim package (Heibl and Calenge 2013).

\section{History and future range changes}

The contemporary species-climate relations were projected for the past, present and three future climate change scenarios using the settings described above. The same bioclimatic variables downloaded from the WorldClim database ${ }^{3}$ were used

\footnotetext{
${ }^{3}$ www.worldclim.org
}

Table 1 Codes of climatic variables developed by Hijmans et al. (2005), variables used in this study in bold

Code Description

bio1 Annual mean temperature

bio2 Mean diurnal range $=$ mean of monthly $(\max$ temp - min temp)

bio3 Isothermality (bio2/bio7) * 100

bio4 Temperature seasonality (standard deviation * 100)

bio5 Max temperature of warmest month

bio6 Min temperature of coldest month

bio7 Temperature annual range (bio5 - bio6)

bio8 Mean temperature of wettest quarter

bio9 Mean temperature of driest quarter

bio10 Mean temperature of warmest quarter

bio11 Mean temperature of coldest quarter

bio12 Annual precipitation

bio13 Precipitation of wettest month

bio14 Precipitation of driest month

bio15 Precipitation seasonality (coefficient of variation)

bio16 Precipitation of wettest quarter

bio17 Precipitation of driest quarter

bio18 Precipitation of warmest quarter

bio19 Precipitation of coldest quarter

in all analyses. The variables based on the coupled global climate models CGCM2 and CGCM3 were used ${ }^{4}$ (Kim et al. 2003) to estimate the future changes in the distribution of suitable climatic niches for $C$. archeri. Three various emission scenarios for 2080 were analyzed: A1b (balance fossil and nonfossil energy sources-CCCMA CGCM3 simulation), A2a (high energy requirements-CCCMA CGCM2 simulation), and $\mathrm{B} 2 \mathrm{a}$ (low energy requirementsCCCMACGCM2 simulation, IPCC Special Report Emissions Scenarios. Summary for Policymakers 2000, to see detailed information about differences between analyzed scenarios see paper previously published by Wiatrowska et al. 2020). This approach was used in numerous recent studies focused on climate change impact on the distribution of various organisms (e.g., Coops and Waring 2011; Ferro et al. 2014, Kukwa and Kolanowska 2016). The bioclimatic data used to evaluate the possible distribution of the studied species during the last glacial maximum (LGM, about 22,000 years ago) were developed and mapped by Paleoclimate Modelling Intercomparison Project Phase II (PMIP2, CCSM; Braconnot et al. 2007).

SDMtoolbox 2.3 for ArcGIS was used to visualize changes in the distribution of suitable climatic niches of studied species caused by global warming (Kremen et al. 2008). To compare the distribution model created for current climatic conditions

\footnotetext{
$\overline{{ }^{4} \text { http://ccafs-climate.org }}$
} 
with future models, all SDMs were converted into binary rasters and mapped using the Goode homolosine projection. The presence threshold value $(0.5)$ was estimated based on the values of grids in which $C$. archeri occurred in models created using present-time data.

\section{Results}

The assessment of the $C$. archeri distribution was made based on the literature, specimens preserved in herbaria, our data collected during field studies and records gathered from open databases. Altogether, a dataset including 146 records of the fungus was created (Fig. 1, Appendix). To show the worldwide predictions of the distribution of the fungus in the past, present and future, we used occurrence information originating from three continents (Australia, Europe and Africa) and New Zealand.

\section{Model evaluation, niche similarity and limiting factors}

The average training area under the ROC (receiver operating characteristic) curve (AUC; DeLong et al. 1988) for the replicate runs received high scores of $0.990-0.994$, indicating that the model performed reliably (Table 2). The AUC has been shown to be prevalence-independent (McPherson et al. 2004), and it is considered to be a highly effective indicator of model performance (Shabani et al. 2016). Among the bioclimatic variables used in this study, precipitation in the driest month was the most important factor affecting the distribution of $C$. archeri in the model based on native records only $(25.8 \%, 2)$ with the optimum volume oscillating near $50 \mathrm{~mm}$ per month (Table 2, Supplementary Material S1). Other climate parameters that influenced this model were the mean temperature of the wettest quarter (up to $9{ }^{\circ} \mathrm{C}$ ) and the precipitation of the warmest quarter (between 100 and $300 \mathrm{~mm}$, Supplementary Material S1). The model generated based on all available records of $C$. archeri indicated that the precipitation in the driest month (optimal value $45 \mathrm{~mm}$ ) was of lowest importance (between $14.7 \%$ and $16 \%$ ), followed by the annual mean temperature (assessed as the $9{ }^{\circ} \mathrm{C}$ maximum) and the maximum temperature of the warmest month (approaching $22{ }^{\circ} \mathrm{C}$, Supplementary Material S2). The contributions of all variables to the MaxEnt models, as described above, are presented in Table 2.

The climatic niches of the native and introduced populations are rather similar according to the climatic niche identity test results $(I=0.957, D=0.797)$. The created PNOs (Supplementary Material S1 and S2) showed relatively small differences in the most suitable values of annual mean temperature (bio1), isothermality (bio3), mean temperature of wettest quarter (bio8), precipitation seasonality (bio15), and precipitation of coldest quarter (bio19) between the native and introduced populations, while significant variations were detected for the temperature seasonality (bio4: 2100-8200 for invasive vs $2800-5800$ in native populations). Overall, the ecological tolerances estimated here based on the values of bioclimatic variables in areas suitable for the occurrence of C. archeri seem to be broader in populations occurring outside the native range of the fungus (see Supplementary Material S1 vs S2).

\section{Past and present distributions}

The estimated range of $C$. archeri during the LGM was broader than that in the present time (Fig. 1b, Fig. 2a). During the glacial period, refugia of the studied fungus were common in Southeastern Australia (including in Tasmania, which was then an integral part of Australia) and most of New Zealand. However, the highest concentration of climatic niches suitable for $C$. archeri in the past was observed on several small islands located near the east coast of Australia, which are now underwater. The current observed potential range of $C$. archeri is smaller by ca. $18 \%$ than it was during the LGM (Table 3). Currently, the distribution of suitable climatic niches of the fungus considerably overlaps with the actual acreage in which the fungus is found in its native range (Fig. 1b). According to the created model, climatic niches of the fungus are distributed in southern Australia and both New Zealand islands, with the highest concentrations observed in the Sydney Basin, southern New South Wales, and the East Coastal Plain in Australia, as well as in Tasmania and the North Island of New Zealand. Interestingly, the analysis conducted based on both native and introduced records indicated some potentially available climatic niches in Madagascar and coastal regions of South Africa. Our model predicted that the climatic conditions of the south coasts of Brazil, Uruguay, and Argentina, as well as some disjunctive locations at the foot of the Andes in Chile, are favorable for C. archeri (Fig. 1a).

The model also showed the existence of numerous climatic niches suitable for the fungus in Europe, where the areas potentially available for the fungus were found in the western, central, and southern portions of the continent. Highly suitable regions that are potentially habitable for $C$. archeri extend from Northern Spain throughout Western and Central Europe to the eastern Polish border and the Carpathian Mountains in the east. Additional suitable habitats were recorded in the Southern Scandinavian Peninsula and the British Isles as well as from the mountainous regions of the Iberian Peninsula, the Dinar Mountains and the Balkans to the southeastern shores of the Black Sea (Fig. 1A).

\section{Future changes in the coverage of suitable habitats}

In our model, over 3.5 million $\mathrm{km}^{2}$ worldwide are currently climatically suitable for $C$. archeri (Table 2). The total area of 

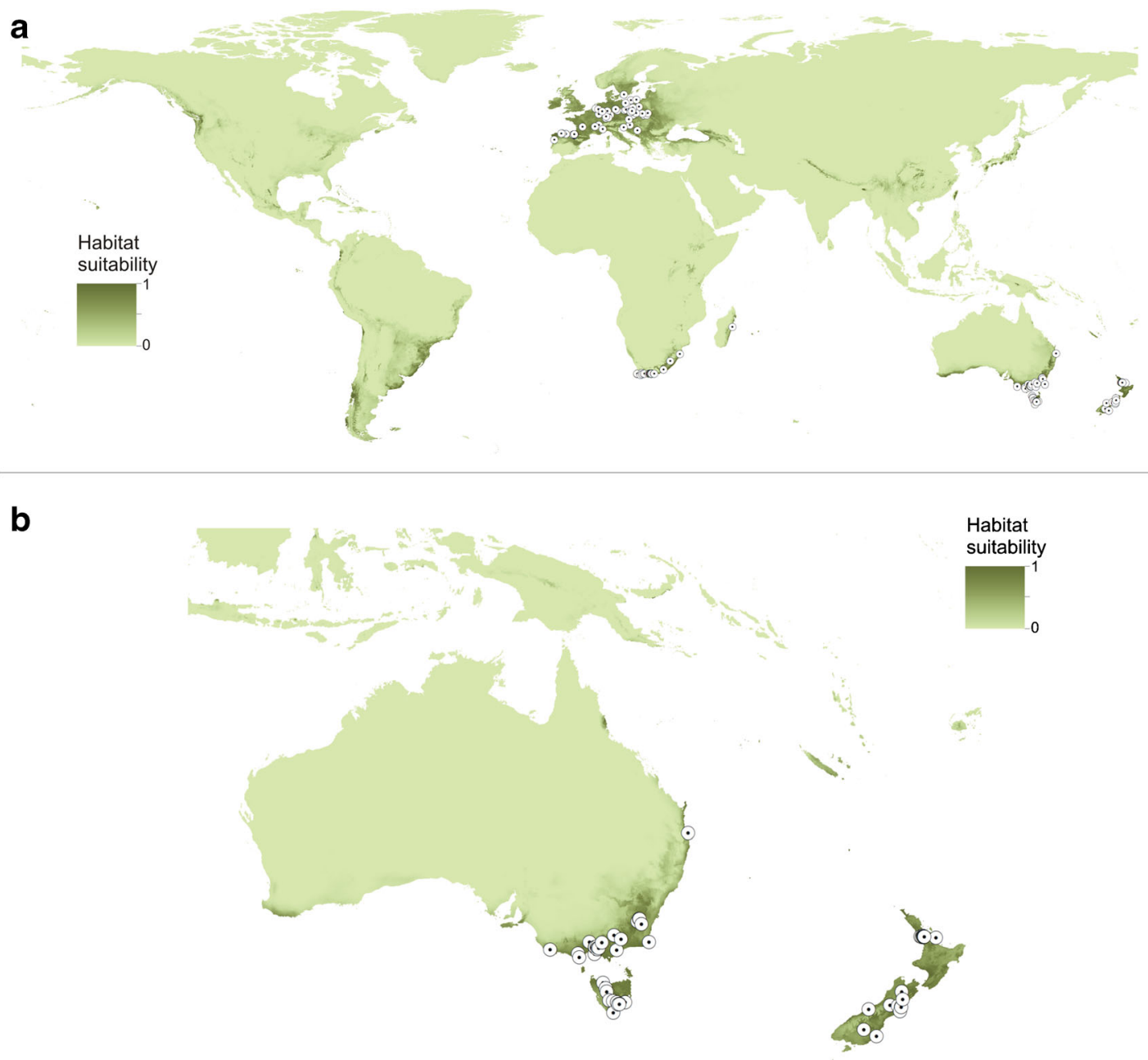

Fig. 1 Present potential distribution of C. archeri: a Global range, b native range. Dots represent localities used in the modelling

the potential occurrence of the fungus is generally expected to decline due to climate change. On a global scale, only one model (Alb scenario; Fig. 3a) projected a small increase (of $6.2 \%$ ) in suitable climatic niches for C. archeri by 2080 (Table 4). Under both scenarios A2a and B2a, the area of preferred habitats is expected to decline, and the highest contraction was anticipated in the A2a scenario (Fig. 3b). This future climatic niche loss was also predicted in the native range of $C$. archeri. All generated models showed significant reductions in suitable habitats in Southeastern Australia, with the highest contraction expected under the Alb scenario (Fig. 2 ). In the pessimistic projection (scenario $\mathrm{A} 1 \mathrm{~b}$ ), the range of C. archeri is expected to be narrowed to the East Coastal Plain. Highly suitable habitats for the fungus will still be

Table 2 The AUC indexes, coverage in native and outside native range and the estimates of relative contributions of the most important environmental variables to the MaxEnt models. Standard deviation values are given in brackets

\begin{tabular}{llllll}
\hline $\begin{array}{l}\text { Model } \\
\text { Dataset }\end{array}$ & LGM & Present & A1b & A2a & B2a \\
Native and nonnative & & $0.994(0.002)$ & $0.993(0.002)$ & $0.990(0.002)$ & $0.994(0.002)$ \\
AUC (SD) & $0.995(0.002)$ & $3,587,973.29$ & $3,824,713.22$ & $2,793,158.65$ & $3,361,766.02$ \\
Coverage $\left[\mathrm{km}^{2}\right]$ & $574,229.3$ & $451,213.60$ & $421,856.36$ & $443,098.93$ & $507,378.98$ \\
Coverage AUS and NZ $\left[\mathrm{km}^{2}\right]$ & $574,229.37$ & $3,136,759.69$ & $3,402,856.87$ & $2,350,059.72$ & $2,854,397.04$ \\
Coverage Beyond native range $\left[\mathrm{km}^{2}\right]$ & - & bio14 (16.0) & bio14 (14.7) & bio14 (15.8) & bio14 (15.4) \\
Var_1 & bio14 (25.8) & bio1 (13.1) & bio1 (14.2) & bio1 (13.3) & bio1 (15.3) \\
Var_2 & bio8 (25.4) & bio5 (12.3) & bio5 (12.8) & bio5 (12.8) & bio5 (13.8) \\
Var_3 & bio18 (8.7) & & & &
\end{tabular}


Table 3 Changes in area suitable for the occurrence of $C$. archeri within its native range $\left[\mathrm{km}^{2}\right]$

\begin{tabular}{|c|c|c|c|c|}
\hline $\begin{array}{l}\text { Range expansion } \\
\text { A }\end{array}$ & $\begin{array}{l}\text { No occupancy } \\
\text { B }\end{array}$ & $\begin{array}{l}\text { No change } \\
\text { C }\end{array}$ & $\begin{array}{l}\text { Range contraction } \\
\text { D }\end{array}$ & $\begin{array}{l}\text { Range change } \\
(\mathrm{C}+\mathrm{D}) /(\mathrm{C}+\mathrm{A})\end{array}$ \\
\hline \multicolumn{5}{|c|}{ LGM vs present $\left[\mathrm{km}^{2}\right]$ (Fig. 2b) } \\
\hline $160,338.98$ & $928,5491.98$ & $413,890.39$ & $69,675.66$ & Contraction $18.7 \%$ \\
\hline \multicolumn{5}{|c|}{ Present vs A1b [km²] (Fig. 2c) } \\
\hline $93,403.62$ & $912,1499.27$ & $328,452.74$ & $122,760.86$ & Contraction $7.0 \%$ \\
\hline \multicolumn{5}{|c|}{ Present vs A2a $\left[\mathrm{km}^{2}\right]$ (Fig. 2d) } \\
\hline $97,269.76$ & $9,117,633.12$ & $345,829.17$ & $10,5384.43$ & Contraction $1.8 \%$ \\
\hline \multicolumn{5}{|c|}{ Present vs B2a [km²] (Fig. 2e) } \\
\hline $125,182.51$ & $9,089,720.38$ & $382,196.46$ & $69,017.14$ & Expansion $11.1 \%$ \\
\hline
\end{tabular}

available in Tasmania and New Zealand, and these regions are predicted to be future refugia for the studied species. Notably, an expansion of suitable climatic niches in the native range of C. archeri was predicted in the $\mathrm{B} 2 \mathrm{a}(11.1 \%)$ climate change scenario (Fig. 2b, Table 3).

According to our analyses, the total loss of suitable habitats for $C$. archeri outside its native range will be observed in Madagascar, South Africa, and eastern South America. In contrast, the future potential range of the fungus in Chile is projected to grow (Fig. 3). All created models revealed the existence of highly suitable areas across the western coast of South America and throughout Patagonia to Cape Horn. Additionally, according to the A1b model (Fig. 3a), preferred habitats will become available in North America (in Newfoundland and Nova Scotia, as well in the northwest region of the continent, from the seaside of British Colombia to the southern coast of Alaska). However, the greatest overlap between the current and future suitable climatic niche aggregates will be observed in Europe (Fig. 3). All future projections showed that the southern part of the European range of C. archeri will become unsuitable for the fungus. In general, losses of available habitats are expected in the Iberian, Apennine, and Anatolian Peninsulas, as well as in Central Europe and the Balkans. The different scenarios predict different degrees of habitat coverage. The most significant reduction in the $C$. archeri range is expected under the A2a scenario (Table 4, Fig. 3b). In terms of total available habitat, the studied species is expected to fare better under the A1b and B2a scenarios than under the other scenarios. The suitable areas estimated by these scenarios are projected to be substantially larger than those predicted by the A2a scenario in the southern range of the fungus, where the model outcomes contradict each other to the greatest extent. On a continental scale, the area of suitable $C$. archeri habitat is generally expected to increase over time as habitat is gained in new regions, especially in northeastern Europe (in the eastern part of the continent and the central and southern parts of the Scandinavian Peninsula), as well in the entire British Isles (Fig. 3). However, our model predicts a notable decline in the global suitable area for the fungus by 2080 under the A2a scenario (Table 4, Fig. 3b).

\section{Discussion}

Species distribution models are rather infrequently used in research on nonpathogenic fungi. Thus far, analyses of the future distributions of these organisms have been implemented in biogeographical studies on Boletales in North America (Pietras et al. 2018; Banasiak et al. 2019; Pietras 2019; Pietras and Kolanowska 2019) and on rare wood-inhabiting saprotrophs restricted to European boreal forests (Kujawska et al. 2021). Therefore, studies of $C$. archeri and its introduction outside of its native range contribute to the discussion on the occurrence of nonpathogenic fungi outside their natural habitats. In this study, we attempted to answer three basic questions regarding the historical occurrence, current biogeography and future distribution changes of $C$. archeri.

\section{Where did C. archeri originate?}

In contrast to plants, fungal micro- and macrofossils are recorded extremely rarely in paleoecological studies. The earliest uncontested fungal fossils are multicellular organic-walled microfossils dating to 1010-890 million years ago, discovered in Arctic Canada (Loron et al. 2019). In general, the lack of paleomycological data confirms that fungi rarely fossilize due to the structures of sporocarps and delicate spores (Ascaso et al. 2005; Beimforde et al. 2014). The environmental DNA of fungi dating back to the LGM can sometimes be detected in glacier sheets using molecular tools (Gavin et al. 2014). Species distribution modelling based on current species records is a useful tool for reconstructing the history of fungi when fossil material is absent. In Australia and Tasmania, species distribution models have been successfully used to reconstruct the occurrence patterns of past refugia, where suitable habitats for endemic plants occurred (Mokany et al. 2017; Das et al. 2019). Our study showed for the first time the 


\section{a}
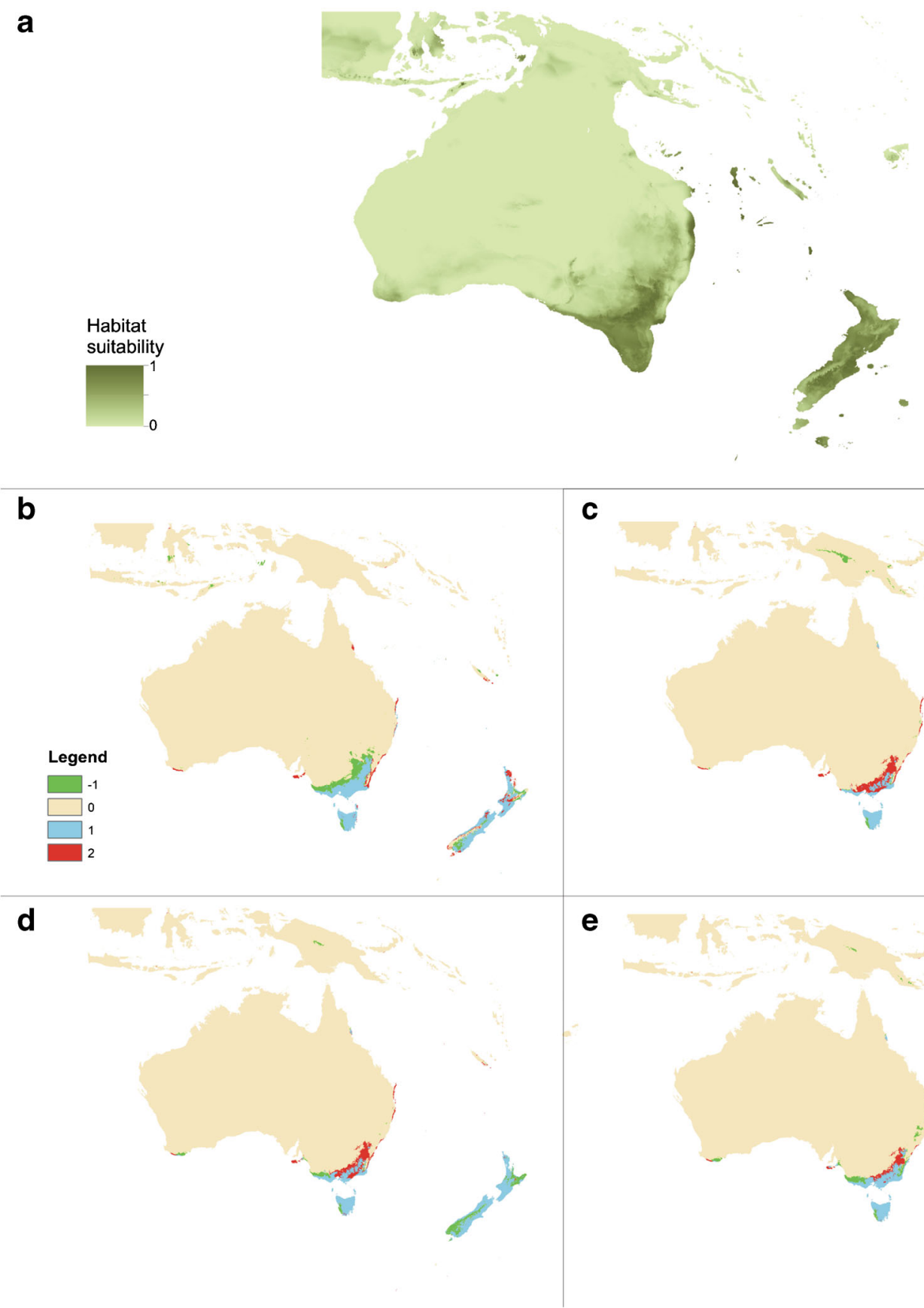

Fig. 2 Potential distribution of C. archeri in its native range during LGM (a) and the changes in area suitable for the occurrence of $C$. archeri between the present and LGM (b), future distribution according to A1b (CCCMA CGCM3 simulation) (c), A2a (CCCMA CGCM2 simulation)

potential distribution of a saprotrophic fungus, C. archeri, 22,000 years ago during the LGM. At that time, the climate throughout eastern Australia was cooler and drier than it is at present (Das et al. 2019). Such conditions were favorable for the broader occurrence of this fungus during the LGM than that at present.

A favorable past environment is also confirmed in our results, showing the precipitation of the driest month and the
C

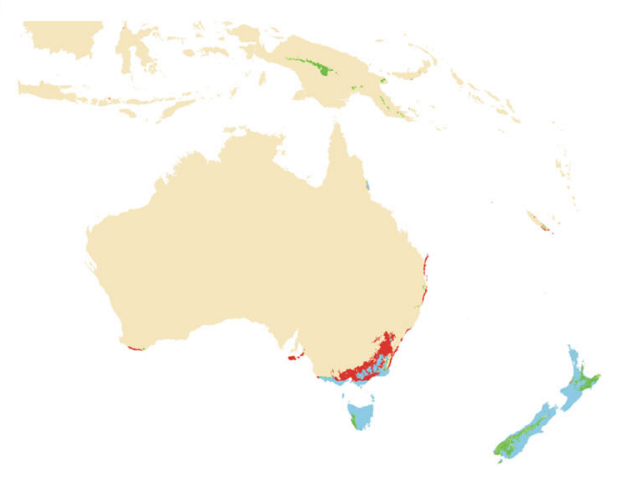

e

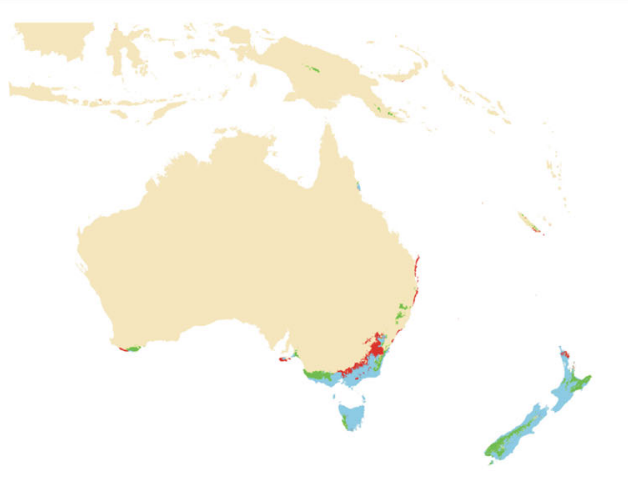

(d) and B2a (CCCMACGCM2 simulation) (e) climate change scenarios. (-1-range expansion, 0 - no occupancy [absence in both], 1-no change presence in both], 2 -range contraction)

mean temperature of the wettest quarter, together contributing more than $50 \%$, as main predictors of $C$. archeri occurrence (Table 2). When the climate becomes warmer and wetter, the range of the fungus decreases to $18.7 \%$ of Australian hot-spot areas (Southeastern Queensland and the North Coast of New South Wales, Das et al. 2019) as well to the southern states of New South Wales and Victoria (Fig. 2b). In contrast, our model indicated that the highly suitable climatic niches of 
Table 4 Changes in area suitable for the global occurrence of C. archeri $\left[\mathrm{km}^{2}\right]$

\begin{tabular}{|c|c|c|c|c|}
\hline $\begin{array}{l}\text { Range expansion } \\
\text { A }\end{array}$ & $\begin{array}{l}\text { No occupancy } \\
\text { B }\end{array}$ & $\begin{array}{l}\text { No change } \\
\text { C }\end{array}$ & $\begin{array}{l}\text { Range contraction } \\
\text { D }\end{array}$ & $\begin{array}{l}\text { Range change } \\
(\mathrm{C}+\mathrm{D}) /(\mathrm{C}+\mathrm{A})\end{array}$ \\
\hline \multicolumn{5}{|c|}{ Present vs Alb [km²] (Fig. 3a) } \\
\hline 2,098,826.09 & $12,9546,234.07$ & $1,725,887.13$ & $1,862,086.15$ & expansion $6.2 \%$ \\
\hline \multicolumn{5}{|c|}{ Present vs A2a $\left[\mathrm{km}^{2}\right]$ (Fig. 3b) } \\
\hline $1,461,942.69$ & $130,183,117.47$ & $1,331,215.96$ & $2,256,757.33$ & contraction $28.5 \%$ \\
\hline \multicolumn{5}{|c|}{ Present vs B2a [km²] (Fig. 3c) } \\
\hline $1,353,516.98$ & $130,291,543.19$ & $2,008,249.04$ & $1,579,724.25$ & contraction $6.7 \%$ \\
\hline
\end{tabular}

C. archeri are located in Tasmania and New Zealand in both the past and present. The wide occurrence of suitable climatic niches during the LGM in New Zealand suggests that $C$. archeri may have occurred in this area during that period (Fig. 2A). Therefore, we hypothesize that $C$. archeri is a likely natural component of the New Zealand mycobiota; however, the natural divergence of the Australian and New Zealand populations could have occurred before the glacial period. This hypothesis needs to be investigated using genetic tools to highlight the differences between the populations and species histories. Population genetic analysis would also reveal demographic events, such as bottlenecks and founder effects,

a

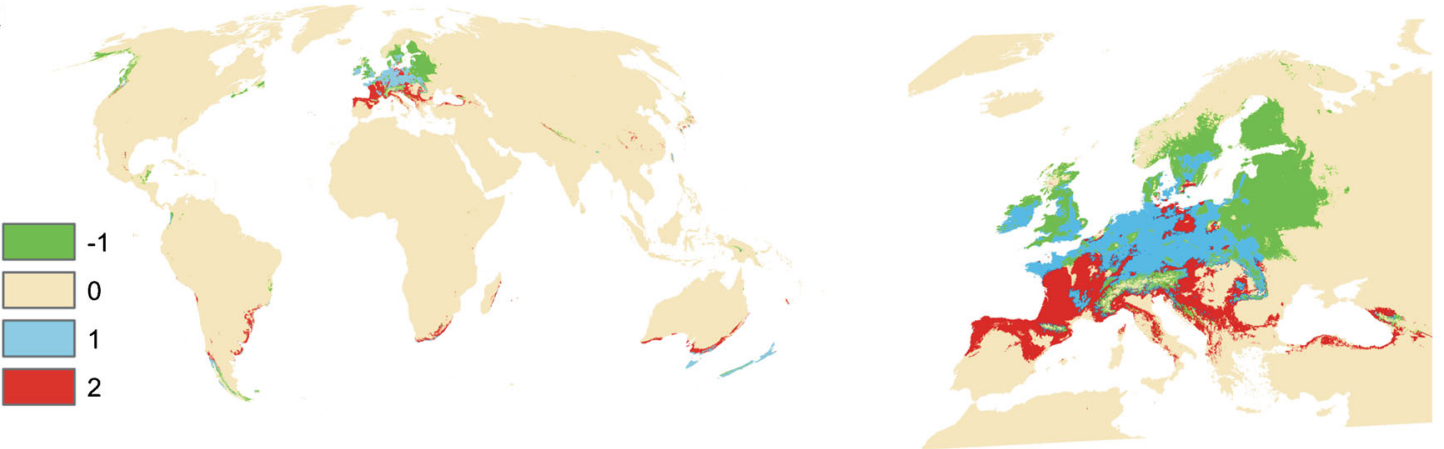

b
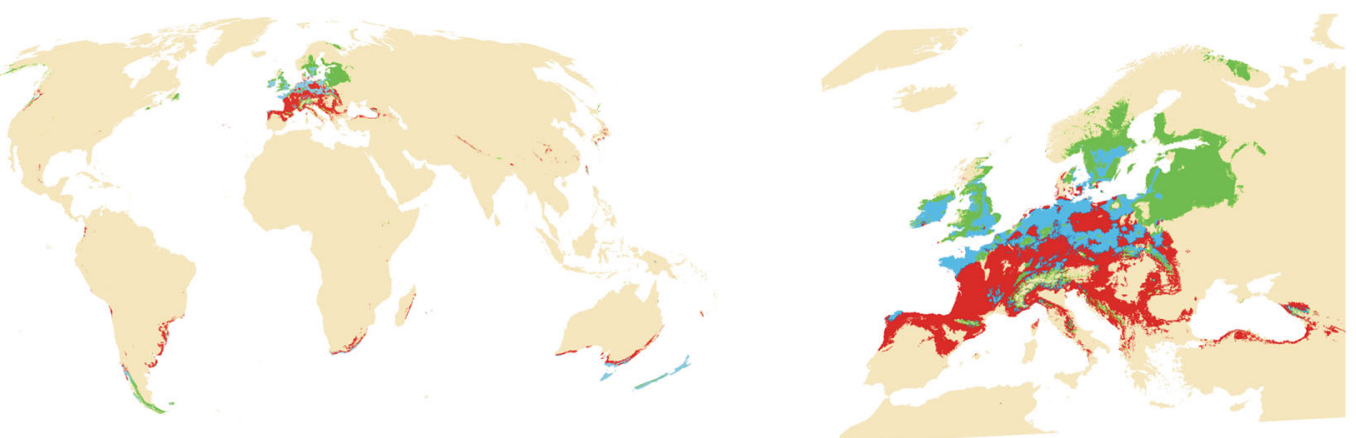

C
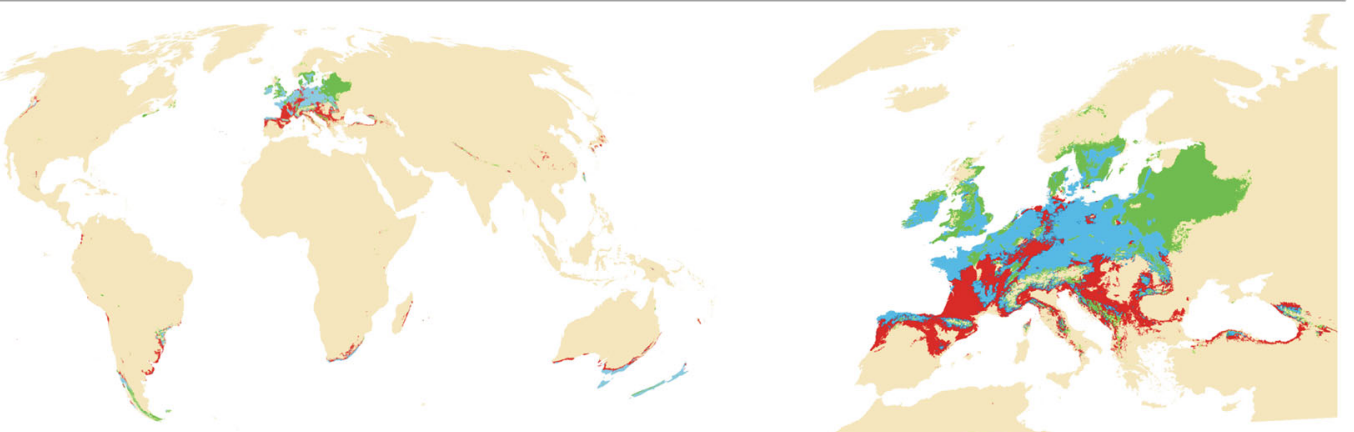

Fig. 3 Changes in the area suitable for the occurrence of $C$. archeri between presence and future according to A1b (CCCMA CGCM3 simulation) (a), A2a (CCCMA CGCM2 simulation) (b) and B2a
(CCCMACGCM2 simulation) (c) climate change scenarios. (- 1range expansion, 0 - no occupancy [absence in both], $1-$ no change [presence in both], 2-range contraction) 
within populations of alien/invasive fungi, which may underlie the invasion success of these fungi (Gladieux et al. 2015; Séne et al. 2018). This approach may also reveal the possibility of the occurrence of cryptic relatives of the fungus, especially in distinct areas where fungal sporocarps can differ in size and morphological features.

\section{How has the fungus found new homes?}

C. archeri was introduced incidentally to Europe in approximately 1920 (Parent and Thoen 1986), probably with Australian wool (Parent et al. 2000) or with Australian soldiers during the First World War (Desprez-Loustau and Rizzo 2011). The probable pathways of $C$. archeri introductions to other parts of the world are unknown. As revealed in the current study, the climatic conditions preferred by the fungus in Europe are comparable to those observed in its native range. The similarity of available habitats allows quick expansion to new areas, as no new adaptation is required, at least for the studied traits of the niches. The broader ecological tolerance of the studied species in its introduced range compared to that in its native range revealed in the PNO analysis also suggests that either the species does not use its fundamental climatic niche completely or that it was able to shift its preferences outside the conditions of its native geographical region. Perhaps the enlargement of its niche was allowed by losses of mortality sources, i.e., the absence of pathogens and parasites of the species (Liu and Stiling 2006). Considering the analyzed variables, populations outside the native range can occur in areas with isothermality (bio3) values of ca. $22-38 \%$ and $45-$ $55 \%$ (native populations are localized within areas with values of ca. $43-53 \%$ only), temperature seasonality (bio4) values of ca. $2100-8200$ (vs 2800-5800), and precipitation seasonality (bio15) values up to $80 \mathrm{~mm}$ (vs up to $40 \mathrm{~mm}$ ).

The current potential range of $C$. archeri in Europe is much broader than its actual occurrence as revealed by the occurrence data (Table 5), further confirming our previous studies showing that the realized niches of nonnative fungi are smaller than the predicted niches (Pietras et al. 2018; Banasiak et al. 2019; Pietras 2019; Pietras and Kolanowska 2019). Our model indicated that numerous suitable habitats are located in Europe, e.g., in the British Isles, Apennine Peninsula, Carpathians, Balkans, and Eastern Europe, where no GBIF records of the fungus are currently available (GBIF.org, 26 October 2018b). Clathrus archeri, similar to other fungi, is a cryptic organism most of the year and is found mostly during field surveys. Ephemeral fruiting bodies make it challenging to detect specimens in field surveys. Moreover, the production of sporocarps strongly depends on climatic conditions, mainly on precipitation during the driest month (Pietras et al. 2016). In contrast to regional scales, where soil conditions become more important, the climate can be considered the most important factor influencing the species distribution at the continental scale (Pearson and Dawson 2003). Precipitation values during the driest or coldest quarters were the most decisive factors influencing the occurrence of suilloid fungi outside their native ranges (Pietras et al. 2018; Pietras 2019; Pietras and Kolanowska 2019). Changes in precipitation during the vegetation season are regarded as crucial drivers affecting the sporocarp production of edible fungi (Taye et al. 2016; Salerni et al. 2014). Precipitation in the coldest month determines the seasonality of sporocarp production. Therefore, this study has shown that the assessed range of C. archeri in Europe is underestimated compared to that determined by specimens observed to date. This assumption can be supported by our latest findings in northern Poland, where, using next-generation sequencing analysis of soil DNA, the presence of $C$. archeri was recorded in sites where no sporocarps had ever been found (Pietras unpublished). Based on the results obtained in this study and our best knowledge about the biology and ecology of $C$. archeri, we conclude that the fungus could be much more prevalent in Europe than previous evidence would indicate.

In the present study, we used an extended dataset of C. archeri records (Appendix), including occurrence data from South Africa and Madagascar (GBIF.org, 26 October 2018c). In these regions, the created models of $C$. archeri occurrence overlapped with the observed range of the fungus. African records were classified as nonnative because they constitute a distant and separated group from the main range of $C$. archeri in Australia and New Zealand. Moreover, sporocarps recorded in Africa indicate different morphological features, mostly consisting of sporocarps colored from red to yellow. There is also no molecular evidence clarifying the phylogenetic relationship between $C$. archeri in its native range and those found in South Africa. Therefore, further molecular studies need to be performed to clarify the taxonomy and systematics of the fungus. Our model also predicted climatic conditions favorable for the fungus in regions where it has never been found (Brazil, Uruguay, Argentina, and Chile). However, sporocarps of $C$. archeri were recently found in other regions of South America (Pinzón-Osorio and PinzónOsorio 2020). Citizen science observations revealed the presence of C. archeri in Bogota Province in Colombia ${ }^{5}$; however, these isolated records could not be included for modelling purposes in this study (Pearson et al. 2006). Similarly, single isolated sites were noted in California in the USA, with the first record of C. archeri occurring in the early 1980s. (voucher no. NY01938977). Apart from the observations above, no other specimens have been preserved in North American fungaria.

\footnotetext{
${ }^{5}$ https://mushroomobserver.org/266860
} 
Table 5 The occurrence of Clathrus archeri in Europe according to all available data submitted to Global Biodiversity Information Facility (GBIF, 31 December 2019) and localities used in this study (records of preserved specimens)

\begin{tabular}{lll}
\hline Country & $\begin{array}{l}\text { Number of all records } \\
\text { submitted to GBIF }\end{array}$ & $\begin{array}{l}\text { Number of records } \\
\text { used in this study }\end{array}$ \\
\hline Poland & 27 & 23 \\
Germany & 370 & 13 \\
Spain & 138 & 13 \\
France & 143 & 2 \\
Netherlands & 831 & 2 \\
Slovenia & 203 & 1 \\
Austria & 50 & 1 \\
Sweden & 32 & 1 \\
Italy & 13 & 1 \\
Luxembourg & 11 & 1 \\
Czech Republic & 9 & 1 \\
Switzerland & 8 & 1 \\
Croatia & 4 & 1 \\
Portugal & 2 & 1 \\
Bosna and Herzegovina & 1 & 1 \\
\hline
\end{tabular}

\section{Quo vadis?}

It is notable that within its native range, the coverage of suitable climatic niches of $C$. archeri has decreased since the LGM, but anthropogenic climate changes have accelerated habitat loss. This process of habitat loss is especially intensive in Australia, where the highest rate of range contraction is expected to occur (Fig. 2c-e). Based on the most pessimistic climate change scenario (A1b), the acreage of optimal habitats of the fungus will decrease to the limited area of the Australian Alps and Coastal Plains in southeast Australia (Fig. 2c). Therefore, $C$. archeri would become a threatened species in all of Australia, even though the IUCN attributes the vulnerable status for saprotrophic fungi whose occupied area tends to decline by more than $30 \%$ over 15-30 years. In contrast, no habitat loss or even range extension is observed in Tasmania and New Zealand, where suitable habitats will still be available in the areas where the fungus potentially occurs; the distribution of the fungus will even enlarge into new regions. Generally, islands are among the most vulnerable to habitats to climate changes regarding shifts in rainfall, temperature, and sea level, including the expected negative influences of these changes on biodiversity (Veron et al. 2019, Office of The Prime Minister's Science Advisory Committee 2013). However, based on the obtained predictions, no negative impacts due to climate change on the distribution of $C$. archeri will be observed in either Tasmania or New Zealand in the future, where a wide range of areas will constitute highly valuable refugia. Different responses to climate change are predicted to occur in the native and introduced ranges of $C$. archeri. In Australia and New Zealand, habitat losses were predicted in the $\mathrm{A} 1 \mathrm{~b}$ and $\mathrm{A} 2 \mathrm{a}$ climate change scenarios, the declines in suitable climatic niche coverages in other parts of the world are expected to occur in the A2a and B2a scenarios. In the most extreme climate simulations, the species will lose $7.0 \%$ (native range)-28.5\% (introduced range) of its preferred habitats. The estimated increase in suitable climatic niche coverage will not be significant within the invasive range $(6.2 \%)$, but it is expected to be twice as high within Australia and New Zealand (11.1\%).

Generally, the most common responses of organisms to climate change in Europe include latitudinal or altitudinal shifts in the geographical distributions of the organisms (Lenoir and Svenning 2015; Gange et al. 2017). For C. archeri, the effect of ongoing climate change is predicted to involve migration from Southwest and Central Europe to areas farther northeast. Additional suitable climatic niches will appear at higher elevations of the Alps and Carpathians (Table 3). The spread of non-pathogenic fungi seems to be unstoppable. Therefore, potential invasion of $C$. archeri should be considered as a possible threat to native mycobiota. Moreover, in the case of the studied fungus, any management strategies proposed by Dickie et al. (2016), such as blocking animal vectors, cannot be used to slow down the expansion of the fungus. The ratio between the areas of contraction and expansion depends on the analyzed climate change scenario. The highest intersection between the current potential and future suitable climatic niche coverages is observed in the B2a scenario, where areas in Central Europe that are suitable for $C$. archeri will be maintained. In contrast, the most pessimistic climate change scenario (A2a, Table 3B) reveals significant habitat loss in the central part of Europe, making the occurrence of the fungus limited mainly to Eastern Europe and several disjointed areas in the central region of the continent.

\section{Conclusion}

Fungi are among the most poorly studied groups of organisms regarding their biogeography and invasion ecology. Based on a worldwide dataset originating from open databases, fungaria, and field observations, we have prepared a comprehensive description of the past, current and future distributions of $C$. archeri. Our study indicated that (1) the area of habitats suitable for the fungus has been decreasing since the LGM and (2) anthropogenic climate change may accelerate the process of habitat loss. Different responses to climate change are predicted to occur in different parts of the world. In the most pessimistic scenario, the highest risks of regional fungal extinction were predicted in Australia and South Africa. As a native species, $C$. archeri should be regarded as a threatened fungus in Australia. In other regions within its native range, climate change will not be entirely detrimental for $C$. archeri, 
and these areas can be regarded as highly valuable future refugia. The expansion of the fungus in Europe is a result of the similarity between the climatic conditions preferred by the fungus in its native range and those in Europe. This similarity allowed a quick expansion of the fungus to new areas, as no adaptation was required. This study also revealed the presence of suitable climatic niches during the LGM in both Australia and New Zealand, supporting the possibility that $C$. archeri is a native species in both countries.

Supplementary Information The online version contains supplementary material available at https://doi.org/10.1007/s11557-021-01669-w.

Acknowledgments We acknowledge the World Climate Research Programme's Working Group on Coupled Modelling, which is responsible for CMIP, and we thank the National Center for Atmospheric Research for producing and making available their model output. For CMIP, the U.S. Department of Energy's Program for Climate Model Diagnosis and Intercomparison provides coordinating support and leads the development of software infrastructure in partnership with the Global Organization for Earth System Science Portals. We thank Dr. Margarita Dueñas (Curator of Herbarium of the MA-Fungi), Dr. Ulrike Damm (Curator of Herbarium of Senckenberg Museum of Natural History, Görlitz), Dr. D. Christine Cargill (Curator of Cryptogam Herbarium Australian National Herbarium, CANB), Pina Milne (Curator of Royal Botanic Garden Victoria Herbarium), Dr. Matthew Pace (Assistant Curator of Herbarium of The New York Botanical Garden). We are grateful to Patric Alber, Bronisław Burza, Anne-Marie Grenier, M. Mayer, Maurice Pelissier, Laura Schneider-Maunoury, Zuzanna Michalska, Sebastian Piskorski and Rozalia Ziółkowska for help in specimen gathering. Special thanks to Prof Ian Dickie, who assisted us in collecting material during our trip to New Zealand.

Authors' contribution All authors contributed to the study conception and design. Material preparation, data collection, and analysis were performed by Marcin Pietras, Marta Kolanowska, and Marc-André Selosse. The first draft of the manuscript was written by Marcin Pietras and all authors commented on previous versions of the manuscript. All authors read and approved the final manuscript.

Funding This study was supported by the Institute of Dendrology Polish Academy of Sciences within statutory activity and the Research Fund for Young Scientists in 2013, by the Ministry of Education, Youth and Sports of CR within the CzeCOS program [grant number LM2018123] and by the Polish National Science Center under the funding of an internship after obtaining a doctoral degree [decision no. DEC-2015/16/S/NZ9/ 00370].

Data availability The authors declare that all data and materials as well as software application support their published claims and comply with field standards.

\section{Compliance with ethical standards}

Competing interests The authors declare that they have no competing interests.

Ethics approval Not applicable.

Code availability Not applicable
Open Access This article is licensed under a Creative Commons Attribution 4.0 International License, which permits use, sharing, adaptation, distribution and reproduction in any medium or format, as long as you give appropriate credit to the original author(s) and the source, provide a link to the Creative Commons licence, and indicate if changes were made. The images or other third party material in this article are included in the article's Creative Commons licence, unless indicated otherwise in a credit line to the material. If material is not included in the article's Creative Commons licence and your intended use is not permitted by statutory regulation or exceeds the permitted use, you will need to obtain permission directly from the copyright holder. To view a copy of this licence, visit http://creativecommons.org/licenses/by/4.0/.

\section{References}

Ascaso C, Wierzchos J, Speranza M, Gutiérrez JC, González AM, de los Ríos A, Alonso J (2005) Fossil protists and fungi in amber and rock substrates. Micropaleontology 51:59-72

Banasiak Ł, Pietras M, Wrzosek M, Okrasińska A, Gorczak M, Kolanowska M, Pawłowska J (2019) Aureoboletus projectellus (Fungi Boletales) - an American bolete rapidly spreading in Europe as a new model species for studying expansion of macrofungi. Fungal Ecol 39:94-99. https://doi.org/10.1016/j. funeco.2018.12.006

Bãžrsan C, Cojocariu A, Cenuåžä E (2014) Distribution and ecology of Clathrus archeri in Romania. Notulae Scientia Biologicae 6:288291

Beimforde C, Feldberg K, Nylinder et al (2014) Estimating the Phanerozoic history of the Ascomycota lineages: combining fossil and molecular data. Mol Phylogenet Evol 78:386-398. https://doi. org/10.1016/j.ympev.2014.04.024

Blackburn TM, Pyšek P, Bacher S et al (2011) A proposed unified framework for biological invasions. Trends Ecol Evol 26:333-339. https://doi.org/10.1016/j.tree.2011.03.023

Braconnot P, Otto-Bliesner B, Harrison S et al (2007) Results of PMIP2 coupled simulations of the mid-Holocene and last glacial maximum - part 1: experiments and large-scale features. Climate of the past 3261-277

Coops NC, Waring RH (2011) Estimating the vulnerability of fifteen tree species under changing climate in Northwest North America. Ecol Model 222:2119-2129. https://doi.org/10.1016/j.ecolmodel.2011. 03.033

Das S, Baumgartner JB, Esperon-Rodriguez M, Wilson PD, Yap J-YS, Rossetto M, Beaumont LJ (2019) Identifying climate refugia for 30 Australian rainforest plant species from the last glacial maximum to 2070. Landsc Ecol 34:2883-2896. https://doi.org/10.1007/s10980019-00924-6

DeLong ER, DeLong DM, Clarke-Pearson DL (1988) Comparing the areas under two or more correlated receiveroperating characteristic curves: a nonparametric approach. Biometrics 44:837-845

Desprez-Loustau ML, Rizzo DM (2011) Fungi. In: Simberloff D, Rejmanek M (eds) Encyclopedia of biological invasions. University of California Press, Barkeley and Los Angeles 261 USA

Desprez-Loustau ML, Robin C, Buée M, Courtecuisse R, Garbaye J, Suffert F, Sache I, Rizzo D (2007) The fungal dimension of biological invasions. Trends Ecol Evol 22:472-480. https://doi.org/10. 1016/j.tree.2007.04.005

Dickie IA, Nunez MA, Pringle A, Lebel T, Tourtellot S, Johnston PR (2016) Towards management of invasive ectomycorrhizal fungi. Biol Inv 18:3383-3395. https://doi.org/10.1007/s10530-016-1243$\mathrm{x}$ 
Dyderski MK, Paź S, Frelich LE, Jagodziński AM (2017) How much does climate change threaten European forest tree species distributions. Glob Chang Biol 24:1150-1163. https://doi.org/10.1111/gcb. 13925

Ferro VG, Lemes P, Melo AS, Loyola R (2014) The reduced effectiveness of protected areas under climate change threatens Atlantic forest tiger moths. PLoS One 9:e107792. https://doi.org/10.1371/ journal.pone. 0107792

Fraiture A, Di Giangregorio M (2013) Amanita inopinata its ecology and expansion in Europe. Cryptogamie Mycol 34:211-222. https://doi. org/10.7872/crym.v34.iss2.2013.211

Gange AD, Heegaard E, Boddy L et al (2017) Trait-dependent distributional shifts in fruiting of common British fungi. Ecosphere 41:5161. https://doi.org/10.1111/ecog.03233

Gavin DG, Fitzpatrick MC, Gugger PF et al (2014) Climate refugia: joint inference from fossil records species distribution models and phylogeography. New Phytol 204:37-54. https://doi.org/10.1111/ nph.12929

GBIF.org (2018a) GBIF Occurrence Download https://doi.org/10.15468/ dl.aye4ni

GBIF.org (2018b) GBIF Occurrence Download https://doi.org/10.15468/ dl.d9ttaf

GBIF.org (2018c) GBIF Occurrence Download https://doi.org/10.15468/ dl.lazkhz

Gladieux P, Feurtey A, Hood ME, Snirc A, Clavel J, Dutech C, Roy M, Giraud T (2015) The population biology of fungal invasions. Mol Ecol 24:1969-1986. https://doi.org/10.1111/mec.13028

González-Moreno P, Diez JM, Richardson DM, Vilà M (2015) Beyond climate: disturbance niche shifts in invasive species. Glob Ecol Biogeogr 24(3):360-370. https://doi.org/10.1111/geb.12271

Guo Y, Li X, Zhao Z, Wei H, Gao B, Gu W (2017) Prediction of the potential geographic distribution of the ectomycorrhizal mushroom Tricholoma matsutake under multiple climate change scenarios. Sci Rep 7:46221. https://doi.org/10.1038/srep46221

Hao T, Guillera-Arroita G, May TW, Lahoz-MonfortaJJ EJ (2020) Using species distribution models for fungi. Fungal Biol Rev 34:74-88. https://doi.org/10.1016/j.fbr.2020.01.002

Heibl C, Calenge C (2013) Phyloclim: integrating phylogenetics and climatic niche modeling. R package version 0.9-4. http://CRAN. R-project.org/package $=$ phyloclim

Hellmann JJ, Byers JE, Bierwagen BG, Dukes JS (2008) Five potential consequences of climate change for invasive species. Conserv Biol 22:534-543. https://doi.org/10.1111/j.1523-1739.2008.00951.x

Hijmans RJ, Cameron SE, Parra JL, Jones PG, Jarvis A (2005) Very high resolution interpolated climate surfaces for global land areas. Int $\mathrm{J}$ Climatol 25:1965-1978. https://doi.org/10.1002/joc.1276

IPCC Special Report Emissions Scenarios. Summary for Policymakers (2000) Intergovernmental panel on climate change (online version https://www.ipcc.ch/site/assets/uploads/2018/03/sres-en.pdf)

Kim SJ, Flato G, Boer G (2003) A coupled climate model simulation of the last glacial maximum part 2: approach to equilibrium. Clim Dyn 2003:635-661. https://doi.org/10.1007/s00382-002-0292-2

Kremen C, Cameron A, Moilanen A et al (2008) Aligning conservation priorities across taxa in Madagascar with high-resolution planning tools. Science 320:222-226. https://doi.org/10.1126/science. 1155193

Kujawska MG, Rudawska M, Stasińska M, Pietras M, Leski T (2021) Distribution and ecological traits of a rare and threatened fungus Hericium flagellum in Poland with the prediction of its potential occurrence in Europe. Fungal Ecol 50:101035. https://doi.org/10. 1016/j.funeco.2020.101035

Kukwa M, Kolanowska M (2016) Glacial refugia and the prediction of future habitat coverage of the south American lichen species Ochrolechia austroamericana. Sci Rep 6:38779. https://doi.org/ 10.1038/srep38779
Lenoir J, Svenning SC (2015) Climate-related range shifts - a global multidimensional synthesis and new research directions. Ecography 38:15-28. https://doi.org/10.1111/ecog.00967

Liu H, Stiling P (2006) Testing the enemy release hypothesis: a review and meta-analysis. Biol Inv 8:1535-1545. https://doi.org/10.1007/ s10530-005-5845-y

Loron CC, François C, Rainbird RH, Turner EC, Borensztajn S, Javaux EJ (2019) Early fungi from the Proterozoic era in Arctic Canada. Nature 570:232-235. https://doi.org/10.1038/s41586-019-1217-0

McPherson J, Jetz W, Rogers D (2004) The effects of species' range sizes on the accuracy of distribution models: ecological phenomenon or statistical artefact? J Appl Ecol 41:811-823

Mokany K, Jordan GJ, Harwood et al (2017) Past present and future refugia for Tasmania's palaeoendemic flora. J Biogeogr 44:15371546. https://doi.org/10.1111/jbi.12927

Moura MR, Villalobos F, Costa GC et al (2016) Disentangling the role of climate topography and vegetation in species richness gradients. PlosOne 11:e0152468. https://doi.org/10.1371/journal.pone. 0152468

Office Of The Prime Minister's Science Advisory Committee (2013) New Zealand's changing climate and oceans: the impact of human activity and implications for the future Auckland New Zealand. (online version: https://www.pmcsa.org.nz/wp-content/uploads/ New-Zealands-Changing-Climate-and-Oceans-report.pdf)

Parent GH, Thoen D (1986) État actuel de l'extension de Clathrus archeri (Berkeley) Dring (syn. : Anthurus archeri (Berk.) Ed. Fischer) en Europe et particulièrement en France et au BÉnÉlux. Bull Trimest Soc Mycol Fr 102:237-272

Parent GH, Thoen D, Calonge FD (2000) Nouvelles données sur la répartition de Clathrus archeri en particulier dans l'Ouest et le Sud-Ouest de l'Europe. Bull Trimest Soc Mycol Fr 116:241

Pearson RG, Dawson TP (2003) Predicting the impacts of climate change on the distribution of species: are bioclimate envelope models useful? Glob Ecol Biogeogr 12:361-371

Pearson RG, Raxworthy CJ, Nakamura M, Townsend PA (2006) Predicting species distributions from small numbers of occurrence records: a test case using cryptic geckos in Madagascar. J Biogeogr 34:102-117. https://doi.org/10.1111/j.1365-2699.2006.01594.x

Phillips SJ, Dudík M, Schapire RE (2004) A maximum entropy approach to species distribution modeling. In: ICML '04. Proceedings of the twenty-first international conference on machine learning. ACM, New York, pp 655-662

Phillips SJ, Anderson R, Schapire RE (2006) Maximum entropy modeling of species geographic distributions. Ecol Model 190:231-259. https://doi.org/10.1016/j.ecolmodel.2005.03.026

Pietras M (2019) First record of North American fungus Rhizopogon pseudoroseolus in Australia and prediction of its occurrence based on climatic niche and symbiotic partner preferences. Mycorrhiza 29: 397-401. https://doi.org/10.1007/s00572-019-00899-x

Pietras M, Kolanowska M (2019) Predicted potential occurrence of the North American false truffle Rhizopogon salebrosus (A.H. Sm.) in Europe. Fungal Ecol 39:225-230. https://doi.org/10.1016/j.funeco. 2018.12.002

Pietras M, Rudawska M, Iszkuło G, Kujawa A, Leski T (2016) Distribution and molecular characterization of an alien fungus Clathrus archeri in Poland. Pol J environ stud 25:1197-1204. https://doi.org/10.15244/pjoes/61230

Pietras M, Litkowiec M, Gołębiewska J (2018) Current and potential distribution of the ectomycorrhizal fungus Suillus lakei ((Murrill) A.H. Sm. \& Thiers) in its invasion range. Mycorrhiza 28:467-475. https://doi.org/10.1007/s00572-018-0836-x

Pinzón-Osorio CA, Pinzón-Osorio J (2020) Primer registro de Clathrus archeri (Berk.) Dring 1980 (Phallales, Clathraceae) para los Andes colombianos. Bol. Cient. MusHist. Nat. U. de Caldas 24:15-24. https://doi.org/10.17151/bccm.2020.24.2.1 
Policelli N, Bruns TD, Vilgalys R, Nuñez MA (2019) Suilloid fungi as global drivers of pine invasions. New Phytol 222:714-725. https:// doi.org/10.1111/nph.15660

Pringle A, Vellinga EC (2006) Last chance to know? Using literature to explore the biogeography and invasion biology of the death cap mushroom Amanita phalloides (Vaill. Ex fr. : Fr.). Biol Inv 8: 1131-1144. https://doi.org/10.1007/s10530-005-3804-2

Pringle A, Adams RI, Cross HB et al (2009) The ectomycorrhizal fungus Amanita phalloides was introduced and is expanding its range on the west coast of North America. Mol Ecol 18:817-833. https://doi.org/ 10.1111/j.1365-294X.2008.04030.x

Radchuk V, Reed T, Teplitsky C et al (2019) Adaptive responses of animals to climate change are most likely insufficient. Nat Com 10:3109. https://doi.org/10.1038/s41467-019-10924-4

Salerni E, Perini E, Gardin L (2014) Linking climate variables with Tuber borchii sporocarps production. Nat Res 5:408-418. https://doi.org/ 10.4236/nr.2014.58038

Schoener TW (1968) The anolis lizards of bimini: resource partitioning in a complex fauna. Ecology 49:704-726

Séne S, Selosse M-A, Forget M et al (2018) A pantropically introduced tree is followed by specific ectomycorrhizal symbionts due to pseudo-vertical transmission. ISME J 12:1806-1816. https://doi. org/10.1038/s41396-018-0088-y

Shabani F, Kumar L, Ahmadi M (2016) A comparison of absolute performance of different correlative and mechanistic species distribution models in an independent area. Ecol Evol 6(16):5973-5986. https://doi.org/10.1002/ece3.2332

Stengl-Rejthar A, Wojewoda W (1985) Expansion of the fungus Clathrus archeri (Berk.) Dring. (Gasteromycetes) in Europe and Poland. Zeszyty Naukowe Uniwersytetu Jagiellońskiego 752. Prace Botaniczne 13:105-110

Suggitt AJ, Lister DG, Thomas CD (2019) Widespread effects of climate change on local plant diversity. Curr Biol 29:2905-2911. https://doi. org/10.1016/j.cub.2019.06.079

Taye ZM, Martínez-Peña F, Boneta JA, de Aragónd JM, de Migue S (2016) Meteorological conditions and site characteristics driving edible mushroom production in Pinus pinaster forests of Central
Spain. Fungal Ecol 23:30-41. https://doi.org/10.1016/j.funeco. 2016.05.008

Vellinga EC, Wolfe BE, Pringle A (2009) Global patterns of ectomycorrhizal introductions. New Phytol 181:960-973. https:// doi.org/10.1111/j.1469-8137.2008.02728.x

Veron S, Mouchet M, Govaerts R, Haevermans T, Pellens R (2019) Vulnerability to climate change of islands worldwide and its impact on the tree of life. Sci Rep 9:14471. https://doi.org/10.1038/s41598019-51107-x

Větrovský T, Kohout P, Kopecký M et al (2019) A meta-analysis of global fungal distribution reveals climate-driven patterns. Nat Com 10:5142. https://doi.org/10.1038/s41467-019-13164-8

Vizzini A, Zotti M, Mello A (2009) Alien fungal species distribution: the study case of Favolaschia calocera. Biol Inv 11:417-429. https:// doi.org/10.1007/s10530-008-9259-5

Walther GR (2010) Community and ecosystem responses to recent climate change. Philos Trans R Soc Lond Ser B Biol Sci 365:20192024

Warren DL, Glor RE, Turelli M (2008) Environmental niche equivalency versus conservatism: quantitative approaches to niche evolution. Evolution 62:2868-2883

Warren DL, Glor RE, Turelli M (2010) ENMTools: a toolbox for comparative studies of environmental niche models. Ecography 33:607611. https://doi.org/10.1111/j.1600-0587.2009.06142.x

Wiatrowska B, Pietras M, Kolanowska M, Danielewicz W (2020) Current occurrence and potential future climatic niche distribution of the invasive shrub Spiraea tomentosa L. in its native and nonnative ranges. Glob Ecol Conserv 24:e01226 https://www. sciencedirect.com/science/article/pii/S2351989420307678

Wisz MS, Hijmans RJ, Li J, Peterson AT, Graham CH et al (2008) Effects of sample size on the performance of species distribution models. Diverv Distrib 14:763-773. https://doi.org/10.1111/j.1472-4642. 2008.00482.x

Publisher's note Springer Nature remains neutral with regard to jurisdictional claims in published maps and institutional affiliations. 